\title{
A dual control strategy for power sharing improvement in islanded mode of AC microgrid
}

\author{
Suleman Haider, Guojie Li $i^{*}$ and Keyou Wang
}

\begin{abstract}
Parallel operation of inverter modules is the solution to increase the reliability, efficiency, and redundancy of inverters in microgrids. Load sharing among inverters in distributed generators (DGs) is a key issue. This study investigates the feasibility of power-sharing among parallel DGs using a dual control strategy in islanded mode of a microgrid. PQ control and droop control techniques are established to control the microgrid operation. P-f and Q-E droop control is used to attain real and reactive power sharing. The frequency variation caused by load change is an issue in droop control strategy whereas the tracking error of inverter power in PQ control is also a challenge. To address these issues, two DGs are interfaced with two parallel inverters in an islanded AC microgrid. PQ control is investigated for controlling the output real and reactive power of the DGs by assigning their references. The inverter under enhanced droop control implements power reallocation to restore the frequency among the distributed generators with predefined droop characteristics. A dual control strategy is proposed for the AC microgrid under islanded operation without communication link. Simulation studies are carried out using MATLAB/SIMULINK and the results show the validity and effective power-sharing performance of the system while maintaining a stable operation when the microgrid is in islanding mode.
\end{abstract}

Keywords: Microgrid, Inverter parallel operation control strategy, Droop control strategy, Frequency restore, Power sharing

\section{Introduction}

The key issues related to microgrids is the parallel operation of different generations in islanded mode [1]. Distributed generators (DGs) during islanding operation of the microgrid are commonly coupled via inverters to an AC distributed system. Various techniques have been introduced for controlling the inverter parallel operation or power-sharing [2]. A microgrid system requires the operation, control structure, power and voltage regulation and energy management [3]. The basic structure of a microgrid contains one or several renewable energy sources (RES), different types of load and energy backup systems integrated together [4]. The actual performance observed when the microgrid operates in islanded mode was presented in [5]. Microgrid control and operation, as well as switching among the different operation

\footnotetext{
* Correspondence: liguojie@sjtu.edu.cn

Department of Electrical Engineering, Shanghai Jiao Tong University, Shanghai 200240, China
}

modes are the main challenges. For increasing the reliability and decreasing the transmission losses the whole microgrid system need be designed to operate under grid connected or islanded mode [6].

In grid connected operation, the microgrid supplies energy to the grid or desired load, charging backup, etc. Hence, the inverter acts as voltage supporter and the distributed power is handled through real power reference which is linked to the generated energy. However, the power flow structure becomes an important aspect [7].

Moreover, in islanded mode, a decentralized droop control method is commonly used with wireless control operation. It is suitable when a number of distributed generators are placed far from each other with no communication connection among them [8]. However, droop control has numerous limitations and challenges, such as voltage drop during load change and frequency variation resulting from the droop principles and is sensitive to distribution line impedance $[9,10]$. 
Furthermore, as the inverters under PQ droop control can operate independently without communication, system redundancy is improved. In case of an inverter failure, the others can continue operating under normal conditions without being affected. The key purpose of this control methodology is to control the whole system in which the DGs are responsible for power delivery [11].

This study considers that all the DGs work as the inverter interface. The losses of the inverters and harmonics are negligible, and two different control strategies for the islanded AC microgrid are presented. The PQ control goal is to adjust the power tracking convergence and to achieve a fast dynamic response. Moreover, the P-f/Q-E droop controller delivers the real and reactive power and provides voltage regulation. A decentralized enhanced droop control method is proposed with frequency restoration scheme (FRS) to restore the frequency and provide the exact real and reactive power.

The rest of the paper is organized as follows. Section II describes the significance of the presented microgrid system, and Section III analyzes PQ control of the inverter and its capability in grid connected operation. Section IV presents the droop method with frequency restoration scheme. In order to achieve power-sharing in a fully decentralized way, Section V presents the combined PQ and droop control strategies and its operation for improving power-sharing in islanding operation of the AC microgrid. Section VI discusses the simulation results while Section VII draws the conclusion.

\subsection{Significance of the presented system}

The presented study combines power regulation between two different control periods set by the supervisory control of the microgrid system. Figure 1 shows the dual control strategies, in which the supervisory control system takes decision according to the operation. It monitors the flow of current into the grid. The absence of current indicates "islanded mode" and the microgrid will assign droop control to balance the voltage. While the presence

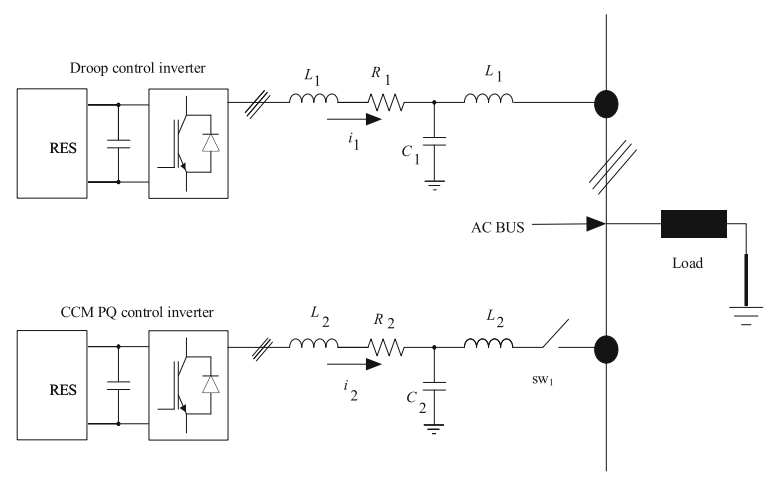

Fig. 1 Parallel structure of micro-grid of current indicates "connected mode" and the microgrid assigns PQ control. When both DGs work together. The balance power at the PCC in islanding operation are $P=P_{1}+P_{2}, Q=Q_{1}+Q_{2}$.

When the microgrid inverters reach the PWM saturation limit and rated power, reactive power demand is fulfilled by the grid-connected droop-controlled inverter. In case of increment in active power, the frequency of the microgrid will drop so the real power of $\mathrm{DG}_{1}$ will increase according to its droop characteristic and at the same time, the reactive power of the parallel DGs will be rearranged.

\section{Methods}

\section{1 $\mathrm{PQ}$ controlled inverter}

In PQ control, the inverter is used to deliver the required real and reactive power according to their set-points. The controller consists of current and power control loops. The inner current loop can rapidly respond to disturbances including input voltage fluctuation, converter dead time and inductance parameter variation. Therefore, the performance of the system is significantly improved [12]. A phaselocked loop (PLL) is used to synchronize the inverter to the microgrid. The RES provides constant real power and reactive power to the grid by $\mathrm{PQ}$ control. The operation of PQ control based on DQ reference frame which defines the components of the $\mathrm{d}$-axis and $\mathrm{q}$-axis $\mathrm{AC}$ currents.

In Fig. 2, the $d$-axis of the reference frame is in-phase with the grid voltage and thus, the d-axis current is responsible for controlling the real power $(\mathrm{P})$ and the $q$ axis current controls the reactive power $(\mathrm{Q})$ of the inverter. The controller consists two loops, i.e. an outer power control loop and an inner current control loop. The main objective of PQ control in the grid-connected inverter is to ensure the inverters to produce the real and reactive power according to their references. Under the $d q$ coordinate system, the inverter output real and reactive power can be described as shown in Fig. 3.

The real and reactive power are decoupled in the power controller block and the current controller adopts

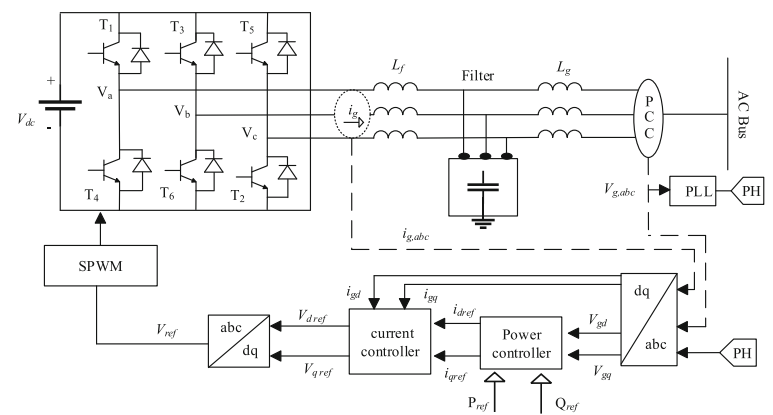

Fig. 2 Grid-connected PQ control inverter 


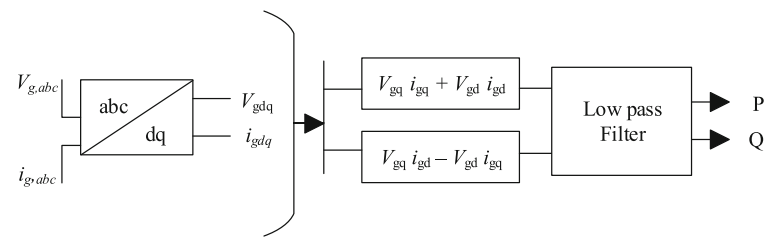

Fig. 3 Power controller schematic

the proportional integral (PI) control. The inverter active and reactive power are controlled by tracking the current references.

$$
\begin{aligned}
& P_{r e f}=V_{g q} i_{g q}+V_{g d} i_{g d} \\
& Q_{r e f}=V_{g q} i_{g d}-V_{g d} i_{g q} \\
& i_{\text {dref }}=\frac{P_{r e f}}{V_{g d}}, i_{\text {qref }}=-\frac{Q_{r e f}}{V_{g d}}
\end{aligned}
$$

Similarly, the inverter current is coupled in terms of $d$ and $q$-axis components as $i_{g d}$ and $i_{g q}$ are affected not only by $V_{g d}$ and $V_{g q}$, but also by the coupled voltages. To independently control $i_{g d}$ and $i_{g q}$, the coupled values need to be canceled. The current control loop uses conventional PI controller and its output is given to the inverter as demanded voltage for switching. The output of the current controller is:

$$
\begin{aligned}
& V_{\text {dref }}=\left(k_{d p}+\frac{k_{d I}}{s}\right)\left(i_{\text {dref }}-i_{g d}\right)-\omega L i_{g q}+V_{g d} \\
& V_{\text {qref }}=\left(k_{q p}+\frac{k_{q I}}{s}\right)\left(i_{q r e f}-i_{g q}\right)+\omega L i_{g d}+V_{g q}
\end{aligned}
$$

When the microgrid is in grid-connected mode, the inverter is in current control mode so the references of the frequency and voltage are both measured by the PLL which also provides the orientation of the synchronous rotating coordinate system.

\subsection{Droop controlled inverter}

Droop control is a well-known method for controlling microgrid in islanded mode. The distributed generation unit is connected to a common bus with the transmission line impedance of $Z=R+j X$ as shown in Fig. 4,

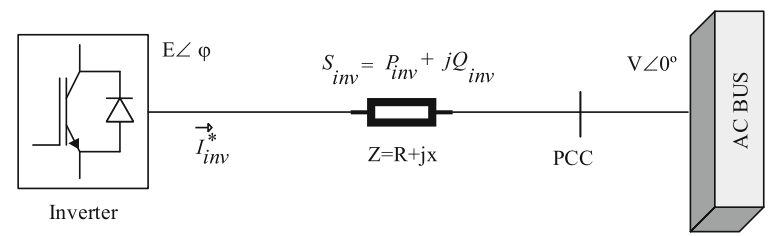

Fig. 4 Equivalent circuit of MG where the apparent power delivered to the $\mathrm{AC}$ bus from the DG is:

$$
S_{i n v}=P_{i n v}+j Q_{i n v}=V_{i n v} I_{i n v}^{*}
$$

In (6), $P$ and $Q$ are the delivered active and reactive power, and $I_{i n v}^{\prime \prime}$ is the current flowing through the line from the DG to the AC bus, which is represented as:

$$
\begin{aligned}
I_{i n v}^{*} & =\frac{E \angle \phi-\mathrm{V} \angle 0}{Z} \\
S_{i n v} & =V\left(\frac{E-V}{Z}\right) \cong \frac{E V}{Z}-\frac{V^{2}}{Z}
\end{aligned}
$$

where $E$ is the inverter voltage and $V$ is the common AC bus voltage. $\phi$ is the phase angle of the inverter side voltage. $\theta=\tan ^{-1}\left(\frac{X}{R}\right)$ is the line impedance angle and $Z$ is the magnitude of the line impedance.

The active power and reactive power are defined as:

$$
\begin{aligned}
& P=\frac{E V}{Z} \cos (\theta-\phi)-\frac{V^{2}}{Z} \cos \theta \\
& Q=\frac{E V}{Z} \sin (\theta-\phi)-\frac{V^{2}}{Z} \sin \theta
\end{aligned}
$$

As seen, the output power depends on the line impedance. For inductive line with $\theta=90^{\circ}$ and $Z \cong X$, the inverter output power is.

$$
\begin{aligned}
& P=\frac{E V}{X} \sin \phi \\
& Q=\frac{V}{X}(E \cos \phi-V)
\end{aligned}
$$

If $X>>R, R$ can be neglected, and if the power angle $\phi$ is small, $\sin \phi \cong \phi$ and $\cos \phi=1$. Thus (11) and (12) become:

$$
\begin{aligned}
& \phi \cong \frac{X P}{E V} \\
& E-V \cong \frac{X Q}{E}
\end{aligned}
$$

Equations (13) and (14) show that the power angle is dependent on real power and the voltage difference depends on reactive power. Thus, the angle can be controlled by regulating the real power while the inverter voltage is controlled by the reactive power.

The real power and power angle regulate the frequency. By adjusting P and Q independently, the voltage amplitude and frequency of the microgrid are regulated. The frequency of the DG drops when the real power of the load increases and the DG voltage amplitude is reduced when the reactive power of the load increases 
[13]. The frequency and the amplitude of the inverter output voltage reference can be expressed as below.

$$
\begin{aligned}
& \omega=\omega^{*}-m\left(P_{c a l}-P^{*}\right) \\
& E=E^{*}-n\left(Q_{c a l}-Q^{*}\right)
\end{aligned}
$$

Equations (15) and (16) determine the frequency and voltage droop regulation relationship through real and reactive power in droop controller. The frequency is determined by droop gain $m$ and the deviation between the calculated real power $\left(P_{\text {cal }}\right)$ and the set-point $P *$ Similarly, the voltage magnitude is determined by the droop gain $n$ and the difference between the calculated reactive power $\left(Q_{c a l}\right)$ and the set-point $Q^{*}$. Thus, (15) shows that load change will cause the frequency to deviate and similarly, (16) shows that the voltage amplitude is reduced when the reactive power of the load increases. Equations (15) and (16) are graphically depicted in Fig. 5.

The real power control loop is closely linked with frequency control and voltage angle. To improve the frequency control accuracy, the frequency restoration scheme (FRS) is applied to restore the frequency to its nominal value $\omega^{*}$. To realize this scheme $\Delta \omega$ is added in (15) as:

$$
\omega=\omega^{*}+\Delta \omega-m\left(P_{c a l}-P^{*}\right)
$$

For steady-state operation, $\Delta \omega=m\left(P_{\text {cal }}-P^{*}\right)$ and thus, $\Delta \omega$ is reformed as:

$$
\frac{d}{d t}(\Delta \omega)=K \cdot \Delta \omega
$$

where $\Delta \omega$ is the frequency error and the constant $K$ controls the overall system frequency restoration.

The frequency restoration scheme is based on Laplace transform of (17) and (18). As it is shown in Fig. 6, the frequency restoration block is added in the droop control diagram. The constant $K$ shows the difference of the vertical moving of the DG. For reducing this variation in the DG, the constant $K$ should be reduced though this does not eliminate the error completely. The FRS will start after smoothing the dynamic response [14].

The reactive power control loop is linked to voltage amplitude and the reactive power-sharing is realized

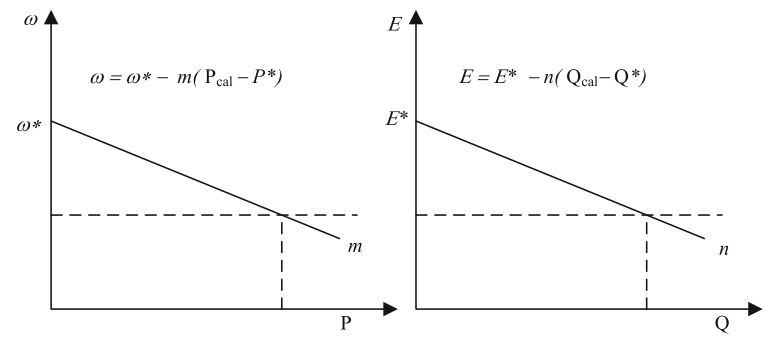

Fig. 5 P-F and Q-E Droop characteristic

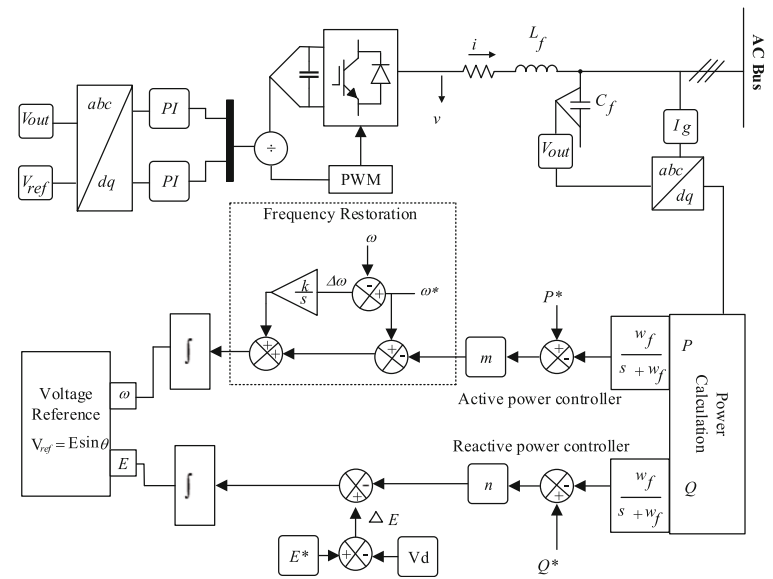

Fig. 6 Enhanced droop control diagram

with the Q-E droop control and is affected by voltage drop and load condition. Thus, (16) becomes

$$
E=\Delta E-n\left(Q_{c a l}-Q^{*}\right)
$$

The voltage amplitude drop is obtained by:

$$
\Delta E=E^{*}-V_{P c c}
$$

Equations (19) and (20) represent the relation between the DG reactive power output and the voltage magnitude difference. The varying range is limited and small for $V_{P C C}$ and thus it assumes the value of $K$ to be a constant slope. Reactive power provided by the DG which is equal to the load side reactive power so $\Delta E$ is reformed as

$$
\Delta E=K\left(E^{*}-V_{P c c}\right)
$$

The voltage drop occurs at the connecting point because the generated reactive power of $D G_{1}$ is higher than that of $\mathrm{DG}_{2}$. Figure 6 shows the control diagram of the enhanced droop control. The output voltage is fed to the inverter through the synchronous reference frame. The output power of the DG is measured and filtered through the low pass filter [15]. The filtered power is given to the droop controller to create voltage magnitude $E$ and the frequency $\omega$. The reference voltage $V_{\text {ref }}=$ $\sin \theta$ is produced in the synchronous reference frame by $\omega$ and $E$. Finally, $V_{\text {ref }}$ is applied to the PWM modulator to generate the PWM signal for the inverter.

In the droop control strategy, the change in load is managed by the distributed generators in a prearranged way and decentralized control of parallel inverters is designed based on the use of the system frequency as a communication link within the microgrid. This method has two problems, i.e. power coupling and slop selection. 
However, power coupling can be avoided through some improve strategies such as virtual power frame transformation or virtual output impedance, though the swapping between the power-sharing and voltage, amplitude, and frequency deviation depends on the selection of the droop coefficient $m$ and $n$.

\section{Dual control performing criteria of MG}

The study is conducted to observe the behavior of the microgrid in islanded operation under different control structures of the parallel inverters. The parallel inverters under combined dual control strategy are unable to perform their task coordinately. To address this issue an enhanced droop controller is proposed to synchronize the inverters at the time when they are connected. In the islanding operation, both voltage and frequency depend on the load. In droop control method the supervisory droop ensures adequate load sharing. However, this results in voltage and frequency variation which may cause undesirable operation of the microgrid. In this section, real and reactive load-sharing issues are discussed for three-phase parallel inverters in the islanded mode of AC microgrid with combined $\mathrm{PQ}$ and droop control strategy.

It is necessary to establish the AC bus voltage and provide the demanded power at the same time. The basic architecture of a microgrid has been shown in Fig. 1, where two distributed generators coordinate under different control scenarios and are able to deliver the power to the desired load according to the corresponding references. In Fig. 7 the flowchart of the control strategy is presented, where the microgrid under combined PQ and proposed enhanced droop control is investigated to verify the proposed Frequency Restoration Scheme (FRS) and voltage control for islanded operation. To verify the dual control, initially, both inverters operate separately and the droop controlled inverter supplies power to the grid $\left(\mathrm{P}_{2}=\mathrm{P}_{\mathrm{G}}\right)$ and the PQ controlled inverter supplies power to the load $\left(\mathrm{P}_{1}=\mathrm{P}_{\mathrm{L}}\right)$. The droop controlled DG is used to regulate the voltage at the PCC. In the islanded operation, initially $\mathrm{DG}_{1}$ connects to the load to provide the desired power to the load during 0 to $0.3 \mathrm{~s}$. After the system is in stable operation, the switch is closed at $0.3 \mathrm{~s}$ so $\mathrm{DG}_{2}$ is connected to the microgrid. $\mathrm{DG}_{1}$ and $\mathrm{DG}_{2}$ then operate together in an islanded mode to deliver the desired power to the load. When the DGs operate together, neglecting the losses, the actual power delivers to the load having the following rule $P_{\text {total }}=\mathrm{P}_{1}+\mathrm{P}_{2}$ where $\mathrm{P}_{\text {total }}$ is the total power consumed by the load.

Note that, when the load changes, $\mathrm{DG}_{1}$ will automatically assign power to the load by the defined droop characteristics. During the whole simulation, the loads are modelled as constant loads. The simulation is carried

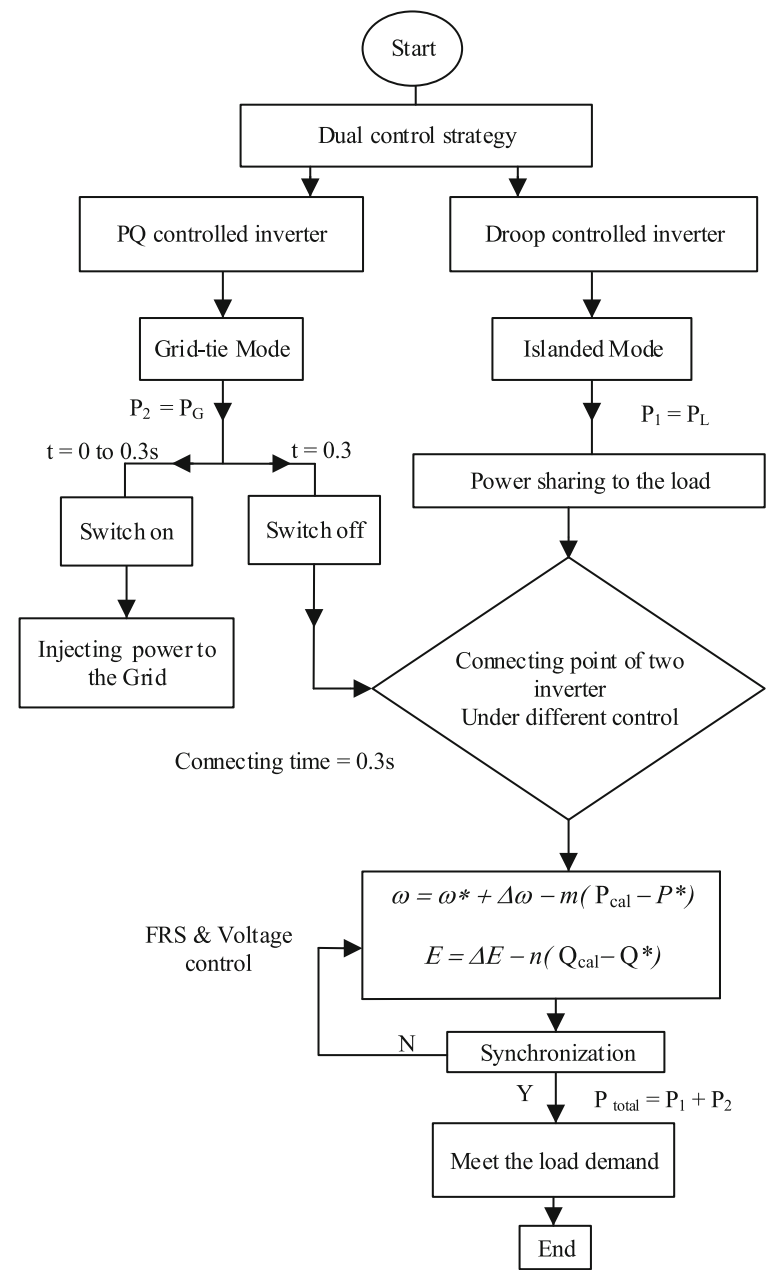

Fig. 7 Flowchart diagram of control strategy

out using Matlab/Simulink and the control parameters of the microgrid are listed in Table 1. The proposed control strategy can be more suitable to achieve efficient power sharing under complex line impedance and with different DG filter parameters. Furthermore, the PQ control goal is to adjust the power tracking convergence and achieve a fast dynamic response. In case of different line impedances, it results in disturbance in power sharing and large current sharing error among the inverters.

\section{Results and discussion}

To verify the effectiveness of the proposed control strategy, islanded operation of the microgrid under the dual control strategy with RL load is investigated. In this study, the microgrid is configured according to Fig. 1 with two interfaced DG units and the nominal AC voltage of $380 \mathrm{~V}$. At the initial study of power regulation performance, $\mathrm{DG}_{1}$ supplies the required real and reactive power to the load under the enhanced droop control 
Table 1 Control parameters

\begin{tabular}{lll}
\hline Contents & DG1 & DG2 \\
\hline DC Source & $800 \mathrm{~V}$ & \\
AC Bus Voltage & $380 \mathrm{~V}$ & \\
Carrier Frequency & $10 \mathrm{kHz}$ & \\
P-f and Q-E Slope Droop & $\mathrm{m}=0.0015, n=0.0001$ & \\
Filter Inductance & $2.5 \mathrm{mH}$ & $2.5 \mathrm{mH}$ \\
Filter Capacitance & $10 \mathrm{uF}$ & $25 \mathrm{uF}$ \\
Resistance of LC Filter & $0.01 \Omega$ & $0.01 \Omega$ \\
DG output power & $10 \mathrm{~kW}$ & $8 \mathrm{~kW}$ \\
& $10 \mathrm{kVar}$ & $5 \mathrm{kVar}$ \\
Inner current loop & $\mathrm{K}_{\mathrm{p}}=2 \mathrm{~K}=0.1$ & $\mathrm{~K}_{\mathrm{p}}=0.3 \mathrm{~K}_{\mathrm{i}}=50$ \\
Nominal Frequency & $50 \mathrm{~Hz}$ & \\
Connecting Time & $T=0.3 \mathrm{~s}$ & \\
\hline
\end{tabular}

strategy as shown in Fig. 6 . During 0 to $0.3 \mathrm{~s}$, the power consumption of the load $\left(\mathrm{L}_{1}\right)$ increases to its rated value $\left(\mathrm{PL}_{1}=8 \mathrm{~kW}, \mathrm{QL}_{1}=5 \mathrm{kVar}\right)$. At $0.3 \mathrm{~s}, \mathrm{DG}_{2}$ connects to the microgrid, which is operated under the PQ control scheme. The responses of the load voltage and current at the PCC are compared in Fig. 8 (a) with conventional droop control and Fig. 8 (b) with enhanced droop control.

It can be seen that at $0.3 \mathrm{~s}$ when the two DGs connect together, a spike appears which is caused by the unexpected variation in reactive power. In Fig. 8 (b), it can be observed that after applying the enhanced droop control, the dynamic responses of voltage and current have been improved. Figure 8 (c) shows the close-up waveforms of the voltage and current with enhanced droop control. At this connecting point, the microgrid starts to synchronize and the increment of the real and reactive power of both inverters can be observed during the synchronization. It can be observed that the frequency at the PCC is increased at the point of synchronization and at the same time the load power is changed. The DG measured power accurately tracks its reference power with fast dynamic response as shown in Fig. 9 for the output power of PQ controlled inverter.

The waveforms of the real and reactive power of the load at the PCC are shown in Fig. 10 and Fig. 11. The frequency increases at the point of synchronization at 0 . 3 s. After synchronization both DGs work together to supply power to the load. The frequency drops because of the load demand, and within $0.2 \mathrm{~s}$ after connection the frequency restores to stable value according to the droop characteristics. The waveforms of the microgrid frequency at the PCC is shown in Fig. 12 (a) and (b) with and without FRS, respectively. The frequency deviation happens because of dual control and droop characteristics. When the load $\left(\mathrm{L}_{2}\right)$ and $\left(\mathrm{L}_{3}\right)$ connect to the

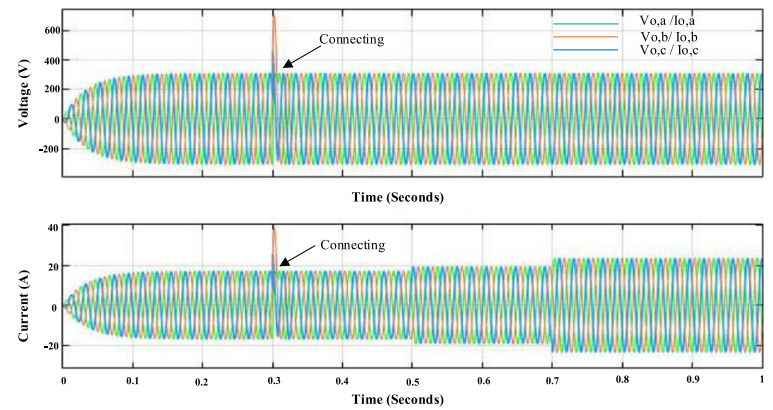

a Output waveform at PCC with conventional droop control

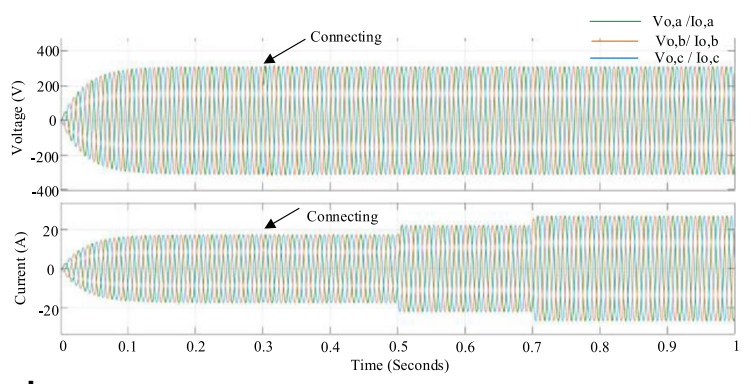

b Output waveform at PCC with enhanced droop control
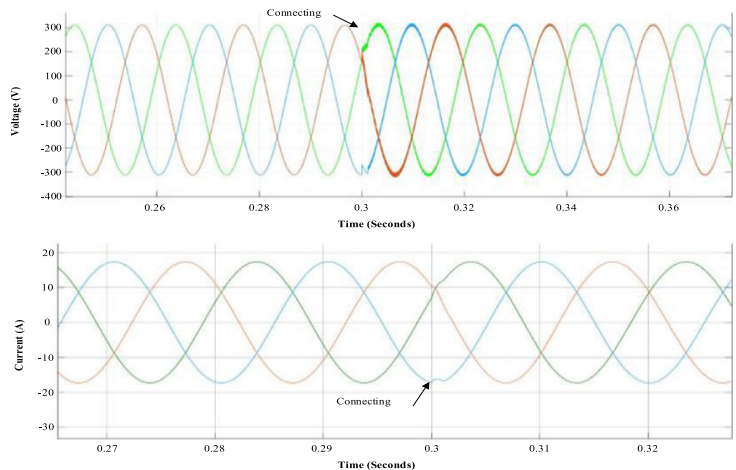

C Close-up output waveform with enhanced droop control

Fig. 8 Output voltage and current waveforms at PCC under the proposed dual-control
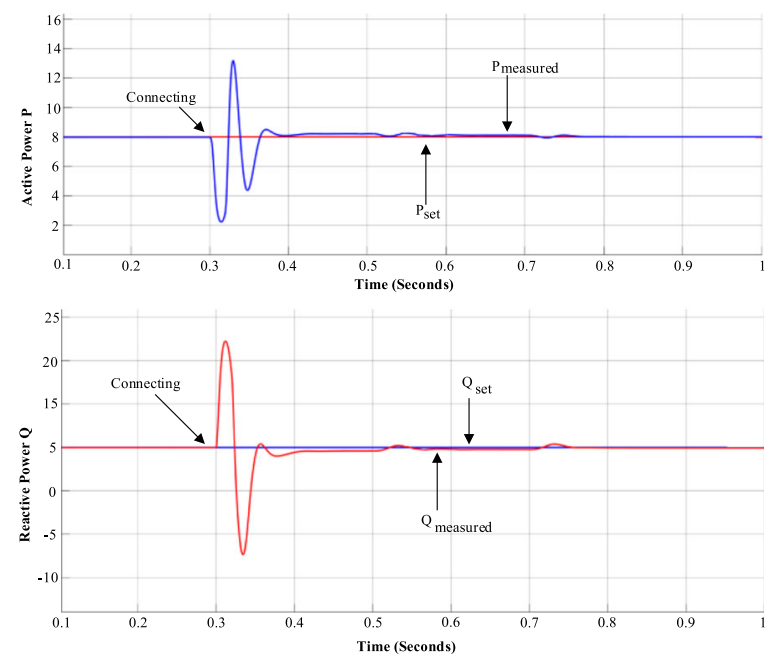

Fig. 9 Tracking output power of $P Q$ control inverter 


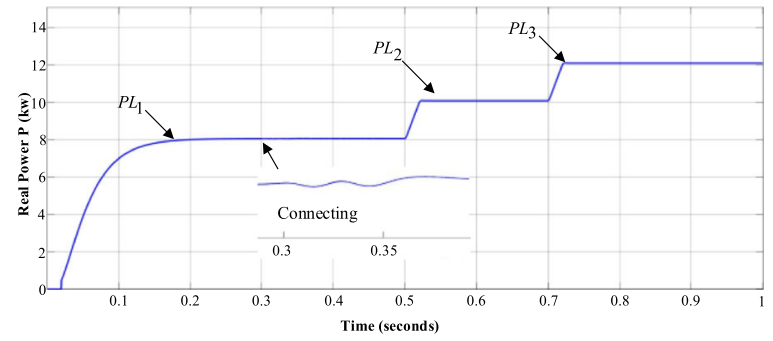

Fig. 10 Active power dynamics response at PCC

microgrid $\left(\mathrm{PL}_{2}=2 \mathrm{~kW}, \mathrm{QL}_{2}=1 \mathrm{kVar}\right),\left(\mathrm{PL}_{3}=2 \mathrm{kw}, \mathrm{QL}_{3}=\right.$ $1 \mathrm{kVar})$, the frequency decreases due to the increased load demand at $0.5 \mathrm{~s}$ and $0.7 \mathrm{~s}$. Thus, the real and reactive power are reallocated through droop controller and consequently $\mathrm{DG}_{1}$ power increases to supply the demand power according to the supervisory droop control. Throughout the load variations, the frequency is at a stable level.

\section{Conclusion}

In this paper, the enhanced droop and PQ control strategies for controlling parallel DGs in islanding mode of AC micro-grids were investigated to achieve flexible power regulation. The main advantage of this dual control strategy is to enable operation without any communication between the parallel DGs. The power tracking error for $\mathrm{PQ}$ control based inverters was investigated and the enhanced droop control implemented with predefined droop characteristics for power reallocation was proposed. To improve and restore the frequency, a frequency restoration scheme (FRS) implemented among the distributed generators was developed. The proposed droop controller provides stable operating under different control strategies in islanded operation and the DG voltage can quickly respond to the required voltage demand. The PQ controller can effectively track the active and reactive power and the droop control provides voltage control in islanded mode. The simulation results obtained from MATLAB/SIMULINK verified the stability of the load voltage and frequency.

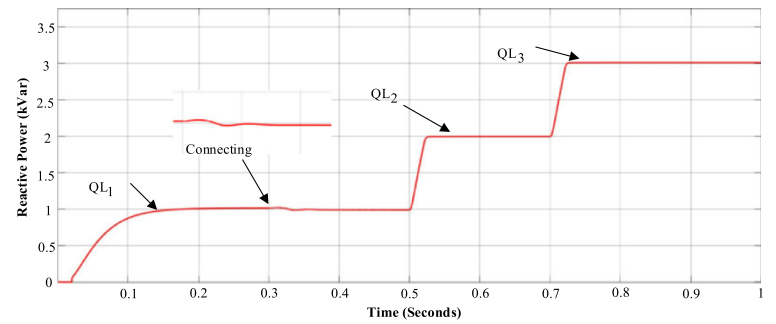

Fig. 11 Reactive power dynamics response at PCC
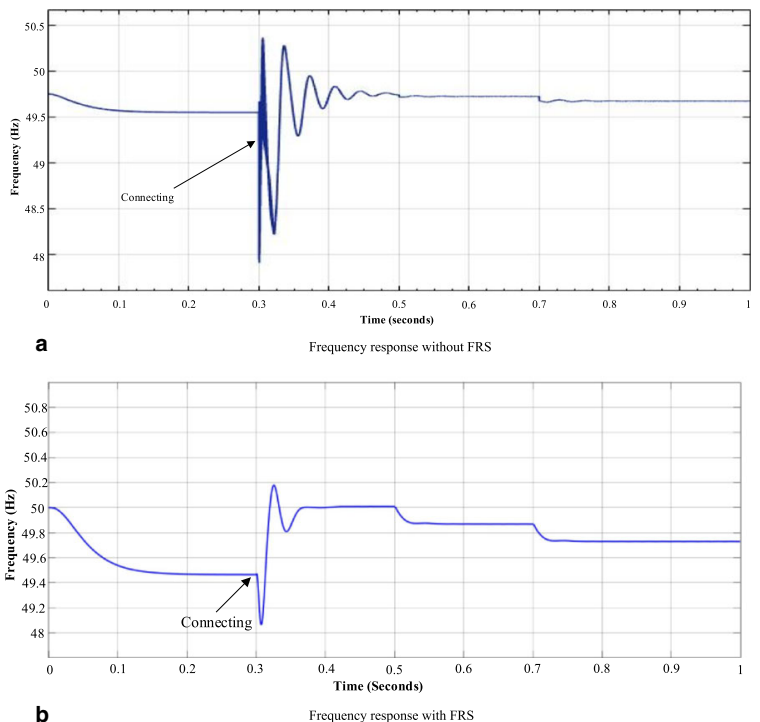

Fig. 12 Frequency variation with and without FRS

\section{Acknowledgements}

This work was supported in part by the National Natural Science Foundation of China under Grant 51477098 and National Key R\&D Program of China (2016YFB0900504).

\section{Authors'contributions}

SH performed the simulation and wrote the draft, GL corresponding, engaged in modifying the paper and submited it to the PCMP. KW checked the grammar and writing of the paper. All authors read and approved the final manuscript.

\section{Competing interests}

The authors declare that they have no competing interests.

Received: 17 August 2017 Accepted: 28 March 2018

Published online: 20 April 2018

\section{References}

1. Parhizi, S., et al. (2015). State of the art in research on micro-grids: A review. IEEE Access, 3, 890-925.

2. Lopes, J. A. P., Moreira, C. L., \& Madureira, A. G. (2006). Defining control strategies for micro-grids islanded operation. IEEE Transactions on Power Apparatus and Systems, 21(2), 916-924.

3. Ahmed, M. N., et al. (2015). An overview on microgrid control strategies International Journal of Engineering and Advanced Technology (IJEAT), 4(5), 93-98.

4. Lasseter, R. H. (2002). Micro-grids. In 2002 IEEE Power Engineering Society Winter Meeting. Conference Proceedings (Cat. No.02CH37309) (Vol. 1, pp. 305-308).

5. Basak, P., Saha, A. K., Chowdhury, S., \& Chowdhury, S. P. (2009). Micro-grid: Control techniques and modeling. 44th International Universities Power Engineering Conference (UPEC), Glasgow IEEE. (pp. 1-5).

6. Jiayi, H., Chuanwen, J., \& Xu, R. (2008). A review on distributed energy resources and micro-grid. Renewable and Sustainable Energy Reviews, 12(9), 2472-2483.

7. Kroposki, B., et al. (2008). Making microgrids work. IEEE Power and Energy Magazine, 6(3), 40-53.

8. Ramezani, M., Li, S., \& Yang, S. (2016). Combining droop and direct-current vector control for control of parallel inverters in micro-grid. IET Renewable Power Generation, 11(1), 107-114.

9. Lu, F., \& Ma, Y. (2015). Simulation design of parallel inverters without interconnections based on improved $\mathrm{PQ}$ droop algorithm. In Industrial Electronics and Applications (ICIEA), 2015 IEEE 10th conference on. IEEE (pp. 719-723). 
10. Guerrero, J. M., Vasquez, J. C., Matas, J., de Vicuna, L. G., \& Castilla, M. (2011). Hierarchical control of droop-controlled AC and DC micro-grids-A general approach toward standardization. IEEE Transactions on Industrial Electronics, 58(1), 158-172.

11. Mahmoud, M. S., Azher Hussain, S., \& Abido, M. A. (2014). Modeling and control of micro-grid: An overview. Journal of the Franklin Institute, 351(5), 2822-2859.

12. Yu, W., Xu, D., \& Ma, K. (2009). The Influence and Design Consideration of UPS Output Virtual Resistance on Parallel-Connected UPS System. In 2009 Twenty-fourth annual IEEE applied power electronics conference and exposition, Washington, DC (pp. 1798-1804)

13. Han, H., Hou, X., Yang, J., Wu, J., Su, M., \& Guerrero, J. M. (2016). Review of power sharing control strategies for islanding operation of AC micro-grids. IEEE Transactions on Smart Grid, 7(1), 200-215.

14. Kosari, M., \& Hosseinian, S. H. (2017). Decentralized reactive power sharing and frequency restoration in islanded micro-grid. IEEE Transactions on Power Systems, 32(4), 2901-2912.

15. Pogaku, N., Prodanovic, M., \& Green, T. C. (2007). Modeling, analysis and testing of autonomous operation of an inverter-based micro-grid. IEEE Transactions on Power Electronics, 22(2), 613-625.

\section{Submit your manuscript to a SpringerOpen ${ }^{\circ}$ journal and benefit from:}

- Convenient online submission

- Rigorous peer review

- Open access: articles freely available online

- High visibility within the field

- Retaining the copyright to your article

Submit your next manuscript at $\boldsymbol{\sim}$ springeropen.com 